\title{
T4 + T3 combination therapy: any progress?
}

\author{
Wilmar M. Wiersinga ${ }^{1}$
}

Received: 15 July 2019 / Accepted: 5 August 2019

(c) The Author(s) 2019

\begin{abstract}
Guidelines on T4 + T3 combination therapy were published in 2012. This review investigates whether the issue is better understood 7 years later. Dissatisfaction with the outcome of T4 monotherapy remains high. Persistent symptoms consist mostly of fatigue, weight gain, problems with memory and thinking and mood disturbances. T4 monotherapy is associated with low serum T3 levels, which often require TSH-suppressive doses of L-T4 for normalization. Peripheral tissue thyroid function tests during T4 treatment indicate mild hyperthyroidism at $\mathrm{TSH}<0.03 \mathrm{mU} / \mathrm{L}$ and mild hypothyroidism at TSH $0.3-5.0 \mathrm{mU} / \mathrm{L}$; tissues are closest to euthyroidism at TSH $0.03-0.3 \mathrm{mU} / \mathrm{L}$. This is explained by the finding that whereas T4 is usually ubiquinated and targeted for proteasomal degradation, hypothalamic T4 is rather stable and less sensitive to ubiquination. A normal serum TSH consequently does not necessarily indicate a euthyroid state. Persistent symptoms in LT4 treated patients despite a normal serum TSH remain incompletely understood. One hypothesis is that a SNP (Thr92Ala) in $\mathrm{DIO} 2$ (required for local production of $\mathrm{T} 3$ out of $\mathrm{T} 4$ ) interferes with its kinetics and/or action, resulting in a local hypothyroid state in the brain. Effective treatment of persistent symptoms has not yet realized. One may try T4 $+\mathrm{T} 3$ combination treatment in selected patients as an experimental $n=1$ study. The 2012 ETA guidelines are still valid for this purpose. More well-designed randomized clinical trials in selected patients are key in order to make progress. In the meantime the whole issue has become rather complicated by commercial and political overtones, as evident from skyrocketing prices of $\mathrm{T} 3$ tablets, aggressive pressure groups and motions in the House of Lords.
\end{abstract}

Keywords Hypothyroidism $\cdot$ Combination therapy $\cdot \mathrm{T} 4 \cdot \mathrm{T} 3$

\section{Introduction}

In 2012 the European Thyroid Association (ETA) published the first guidelines on $\mathrm{T} 4+\mathrm{T} 3$ combination therapy in hypothyroidism [1]. It is now 7 years later, and one wonders if any progress has been made. I would like to address this issue by asking the same questions as in the 2012 guidelines.

\section{Is there an unmet need in L-T4 treated hypothyroid patients?}

In 2012 it was reported that 5-10\% of L-T4 treated hypothyroid patients with normal serum TSH have persistent

Wilmar M. Wiersinga

w.m.wiersinga@amc.uva.nl

1 Department of Endocrinology \& Metabolism, Academic Medical Center, University of Amsterdam, Amsterdam, The Netherlands symptoms (impaired well-being, psychological distress and cognitive disturbances) that can be related to the thyroid disease and L-T4 therapy [1]. This statement was based on three population-based studies from the UK, the Netherlands and Norway [2-4]. Since then there have been no more studies in the general population, but in 2017 an online survey for hypothyroid patients posted on the American Thyroid Association (ATA) website demonstrates prominent dissatisfaction with treatment [5]. Among respondents without self-reported depression, life stressors, or medical conditions $(n=3670)$, satisfaction on a scale of 1-10 with L-T4 was 5 (IQR 3-7), satisfaction with L-T4 + L-T3 was 6 (IQR 3-8), and satisfaction in patients taking desiccated thyroid extract (DTE) was highest (score 7, IQR $5-9)(p<0.0001)$. Among those who were frustrated with their treatment $(\sim 22 \%$ of respondents taking L-T4 or L-T4 + L-T3, and $14 \%$ of DTE users), the relevant areas identified as causing dissatisfaction were fatigue or energy level $(77 \%)$, weight management $(69 \%)$, memory or other problems with thinking (58\%), and mood (45\%) [5]. The survey results are probably biased as dissatisfied patients are 
more likely to have participated in the survey than patients who felt happy with their treatment. Another bias might be a relatively high proportion of subclinical hypothyroidism among the participants, since thyroxine replacement in the last decades is initiated at progressively lower serum TSH concentrations (in 2009 at a median TSH of $7.9 \mathrm{mU} / \mathrm{L}$ ) [6]. Recent trials have not shown improvement in thyroidrelated symptoms or quality of life after levothyroxine treatment of subclinical hypothyroidism, especially not in older individuals [7-9]. Dissatisfaction with treatment outcome could thus be related to inclusion of many older patients with subclinical hypothyroidism.

\section{Is there a biologic rationale for persistent complaints in L-T4 treated hypothyroid patients?}

In 2012 five possible causes of persistent complaints were identified [1].

\section{Nonspecific causes related to the chronic nature of the disease}

Awareness of having a chronic disease and lifelong dependency of thyroid medication could make patients unhappy and less healthy [1]. There have been no prospective studies to test the hypothesis that attitudes, health perceptions and mood of patients prior to L-T4 treatment differ between those with and without persistent complaints after treatment. Qualitative interview studies show that patients in general have a low understanding of their condition [10]. When they experience hypothyroid symptoms at initial diagnosis, the perception of disease susceptibility (and adherence to L-T4) is better, but patients who remain unwell despite a normal serum TSH felt that their normal result presented a barrier to further evaluation. Qualitative studies among general practitioners and nurses reveal inadequate knowledge of medication interactions and L-T4 pharmacokinetics [11].They rely on blood tests over clinical symptoms to adjust L-T4 dose. Information exchange is usually restricted by time and often centered on symptoms rather than patient education. Poor adherence was felt to be the main reason for suboptimal treatment, although other factors such as comorbidity and comedication were mentioned. It follows that improvement of the interaction between physicians and patients could reduce barriers to optimal thyroid replacement.

\section{Associated autoimmune diseases}

Associated autoimmune diseases occur in $14 \%$ of patients with Hashimoto's disease and in $10 \%$ of patients with
Graves' disease [12]. It is unknown how often overlooked associated autoimmune diseases are responsible for persistent complaints.

\section{Thyroid autoimmunity per se}

Whether or not thyroid autoimmunity per se might be responsible for particular symptoms, remains unclear. For instance, the mere presence of TPO antibodies in otherwise euthyroid subjects has been linked to depression in some population-based studies but not in others [1]. Complete removal of thyroid antigens by total thyroidectomy induces progressive disappearance of thyroid antibodies. To determine whether thyroidectomy improves symptoms which persisted in patients with Hashimoto thyroiditis despite having normal thyroid function tests while receiving thyroid hormone replacement therapy, a randomized clinical trial was done comparing total thyroidectomy with continuation of medical therapy [13]. Total thyroidectomy improved health-related quality-of-life and fatigue, whereas medical therapy did not. At 18 months, median TPO-Ab values were reduced from 2232 to $152 \mathrm{kU} / \mathrm{L}$ in the surgical group and from 2052 to $1300 \mathrm{kU} / \mathrm{L}$ in the medical group.

\section{Inadequacy of L-T4 dose}

In accordance with previous studies, NHANES participants using L-T4 and having a normal serum TSH, experience higher total and free T4 and lower total and free T3 serum concentrations than healthy or matched controls [14]. FT3 values below the lower normal limit are observed in about $15 \%$ of hypothyroid patients on L-T4 [15]. One may thus question whether low serum T3 levels could be involved in persistent complaints, necessitating higher L-T4 doses to normalize T3 levels. This seems, however, not very likely. Slightly lower or higher L-T4 doses did not produce measurable changes in hypothyroid symptoms, well-being or quality of life $[16,17]$, nor in substantial metabolic differences [18]. Another study evaluated the effect of total thyroidectomy, which abolishes thyroidal T3 secretion [19]. Postoperative FT3 levels during L-T4 replacement were compared with preoperative native serum FT3 in the same individuals: postoperative FT3 was higher than preoperative FT3 in subjects with postoperative TSH $<0.03 \mathrm{mU} / \mathrm{L}$, unchanged in subjects with postoperative TSH $0.03-0.3 \mathrm{mU} / \mathrm{L}$, and lower in subjects with postoperative TSH $0.3-5.0 \mathrm{mU} / \mathrm{L}$ [19]. These studies suggest that TSHsuppressive doses of L-T4 are required to achieve serum T3 levels similar to those before thyroidectomy. It provides a rationale for T3 supplementation [20]. However, there is no good evidence that low serum T3 or low FT3/FT4 ratios are linked to persistent symptoms. The mechanism responsible for the low serum T3 during L-T4 therapy has to do with 
type 2 iodothyronine deiodinase (DIO2). This enzyme catalyzes the deiodination of T4 into T3 in extrathyroidal tissues thereby sustaining serum T3 levels during L-T4 replacement. DIO2 has a short half-life $(\approx 60 \mathrm{~min}$.) that becomes even shorter $(20 \mathrm{~min}$.) by interacting with $\mathrm{T} 4$, which results in DIO2 ubiquitination and targeting for proteosomal degradation [21]. DIO2 in the hypothalamus, in contrast to other tissues, is rather stable and less sensitive to ubiquitination [22]. Thus, whereas in the rest of the body $\mathrm{DIO} 2$-mediated $\mathrm{T} 3$ production progressively decreases with increasing L-T4 doses because of DIO2 ubiquitination, T3 production in the hypothalamus/pituitary is not and the dose of L-T4 required to normalize serum TSH is lower than the dose that normalizes serum T3. It follows that in order to reach a normal serum $\mathrm{T} 3$, one has to administer a relatively high L-T4 dose that is likely to suppress serum TSH.

\section{Inadequacy of L-T4 treatment modality}

Peripheral tissue thyroid function tests have been evaluated before total thyroidectomy and at 1 year postoperatively when using L-T4 [23]. Patients who had postoperative $\mathrm{TSH} \leq 0.03 \mathrm{mU} / \mathrm{L}$, were mildly hyperthyroid at tissue level, those with TSH between 0.03 and $0.3 \mathrm{mU} / \mathrm{L}$ had peripheral tissue function tests closest to euthyroidism, and those with TSH between 0.3 and $5.0 \mathrm{mU} / \mathrm{L}$ had mild tissue hypothyroidism (Table 1). L-T4 replacement in doses that normalize serum TSH, do not normalize all systemic markers of thyroid hormone signaling, including serum LDL cholesterol and total cholesterol [24]. A normal serum TSH is thus no guarantee for a euthyroid state in all target tissues $[15,25]$. One must conclude that L-T4 therapy is incapable to achieve euthyroidism simultaneously in all target tissues, precisely the conclusion reached by the Escobar's in their now famous experiments on thyroid hormone replacement in hypothyroid rats: only the combination of L-T4 + L-T3 could ensure simultaneous euthyroidism in all tissues [1]. Although L-T4 may not be the ideal form of thyroid hormone replacement, the vast majority of patients are satisfied with its outcome. Why a subset of patients keeps persistent symptoms, remains incompletely understood. It has been hypothesized that a particular single nucleotide polymorphism (SNP) in DIO2 is involved, namely Thr92Ala. Interest in this SNP was raised by the early finding that Thr92Ala was associated with impaired psychological wellbeing on L-T4 therapy and enhanced response to T4 $+\mathrm{T} 3$ combination therapy [26]. Up to $80 \%$ of intracellular T3 in brain is derived from local deiodination of $\mathrm{T} 4$ into $\mathrm{T} 3$ catalyzed by D2. Some studies demonstrate reduced D2 activity in the presence of Thr92Ala [27], but others observe normal enzyme kinetics of the SNP [28]. A Dutch population-based study reports that the Ala/Ala genotype of this D2 polymorphism is present in $11.3 \%$ of $\mathrm{T} 4$ users and in $10.7 \%$ of the general population; in both groups the SNP is associated neither with differences in serum TSH, FT4, FT3, or FT3/FT4 ratio, nor with health-related quality of life and cognitive functioning [29]. Recently the cellular abnormalities associated with the Thr92Ala protein have been explored further. The Ala92 version of the protein has a longer half-life than the wild type, is ectopically localized in the Golgi apparatus, and alters the genetic profile of certain areas of the human brain in a pattern reminiscent of neurodegenerative disease, without evidence of reduced thyroid hormone signaling [30]. The latest study reports D2 is a cargo protein, recycling between ER and Golgi [31]. The Thr92-to-Ala substitution causes ER stress, activates the unfolded protein response (UPR), accumulates in the trans-Golgi, and generates less T3. Mouse carrying Ala92 DIO2 exhibit UPR and hypothyroidism in distinct brain areas, whereas exogenous L-T3 improves cognition. Primary hypothyroidism intensifies the Ala92 DIO2 phenotype, with only partial response to L-T4. One has to
Table 1 Peripheral tissue thyroid function tests in 133 patients before total thyroidectomy and at one year postoperatively under L-T4 medication [23]

\begin{tabular}{|c|c|c|c|}
\hline Postoperative TSH & $\begin{array}{l}\leq 0.03 \mathrm{mU} / \mathrm{L} \\
(n=58)\end{array}$ & $\begin{array}{l}0.03 \text { to } \leq 0.3 \mathrm{mU} / \mathrm{L} \\
(n=46)\end{array}$ & $\begin{array}{l}0.3 \text { to } \leq 5.0 \mathrm{mU} / \mathrm{L} \\
(n=29)\end{array}$ \\
\hline & Preop $\rightarrow$ postop & Preop $\rightarrow$ postop & Preop $\rightarrow$ postop \\
\hline TSH mU/L & $1.48 \rightarrow 0.01 \downarrow$ & $1.56 \rightarrow 0.07 \downarrow$ & $1.59 \rightarrow 1.51 \mathrm{NS}$ \\
\hline FT4 ng/dl & $1.07 \rightarrow 1.56 \uparrow$ & $1.09 \rightarrow 1.45 \uparrow$ & $1.12 \rightarrow 1.38 \uparrow$ \\
\hline FT3 pg/ml & $2.79 \rightarrow 3.17 \uparrow$ & $2.92 \rightarrow 2.96 \mathrm{NS}$ & $2.92 \rightarrow 2.76 \downarrow$ \\
\hline Thyroid state in serum postop. & $\rightarrow$ Hyperthyroid & $\begin{array}{l}\rightarrow \text { Subclinical } \\
\text { hyperthyroid }\end{array}$ & $\rightarrow$ Euthyroid \\
\hline LDL-C mg/dl & $114 \rightarrow 111 \mathrm{NS}$ & $104 \rightarrow 104 \mathrm{NS}$ & $108 \rightarrow 114 \uparrow$ \\
\hline SHBG nmol/l & $69 \rightarrow 82 \uparrow$ & $66 \rightarrow 66 \mathrm{NS}$ & $67 \rightarrow 72 \mathrm{NS}$ \\
\hline TRACP mU/dl & $377 \rightarrow 371 \mathrm{NS}$ & $361 \rightarrow 328 \mathrm{NS}$ & $362 \rightarrow 319 \downarrow$ \\
\hline BAP $\mu \mathrm{g} / \mathrm{dl}$ & $13 \rightarrow 15 \uparrow$ & $13 \rightarrow 13 \mathrm{NS}$ & $15 \rightarrow 14 \mathrm{NS}$ \\
\hline Thyroid state in tissues postop. & $\rightarrow$ Mild hyperthyroid & $\rightarrow$ Closest to euthyroid & $\rightarrow$ Mild hypothyroid \\
\hline
\end{tabular}

$L D L-C$ LDL-cholesterol, SHBG sex hormone binding globulin, TRACP tartrate-resistant acid phosphatase, $B A P$ bone alkaline phosphatase, $N S$ not significant, $\downarrow$ significant fall, $\uparrow$ significant rise 
conclude that the origin of persistent complaints in L-T4 treated hypothyroid patients who have a normal serum TSH, is still incompletely understood. On the other hand, one can also conclude that L-T4 monotherapy is unlikely to be the ideal mode of thyroid hormone replacement. A 2013 survey among endocrinologists indicated that persistent symptoms despite achieving target TSH values, would prompt testing for other causes by $84 \%$ of respondents, a referral to primary care by $11 \%$, and a change to L-T4 + L-T3 combination therapy by $3.6 \% ; 22 \%$ would ask for measurement of T3 [32].

\section{Is there evidence that L-T4 + L-T3 combination therapy serves the hypothyroid patient better than L-T4 monotherapy?}

A 2006 meta-analysis of 11 RCTs comparing L-T4 monotherapy with L-T4 + L-T3 combination therapy found no differences in various outcome measures (quality of life, cognition, mood or symptoms) [1]. Adverse events also did not differ between both regimens. The most recent RCT likewise finds no differences [33]. Many if not all RCTs can be criticized on a number of issues, e.g. selection bias due to inclusion of heterogeneous patient groups by etiology and prognosis, dilution of the true effect by low proportion of symptomatic patients, small sample size, misguided TSH targets, confounding caused by variation in T4 to T3 conversion efficiency, wide variation in treatment response, small effect size on the QoL instrument [34]. In seven of the RCTs patients were asked about their preference for a specific treatment period: $48 \%$ preferred $\mathrm{T} 4+\mathrm{T} 3$ therapy, $25 \%$ preferred T4 therapy, and $27 \%$ had no preference [1]. Patients randomized to receive $\mathrm{T} 4+\mathrm{T} 3$ lost $0.5-1.5 \mathrm{~kg}$ whereas those randomized to $\mathrm{T} 4$ gained $0.1-0.5 \mathrm{~kg}$. Recent studies, however, could not confirm a relationship between preferences and changes in body weight [35, 36]. All guidelines state L-T4 should remain the treatment of choice for hypothyroid patients [37].

\section{Could it be that trials comparing L-T4 + L-T3 combination therapy and L-T4 monotherapy have not targeted the right population?}

This is very well possible. Outcomes might be different by applying different selection criteria. New RCTs can be envisaged restricted to patients with persistent symptoms and/or specific genotypes like Thr92Ala DIO2. Other polymorphisms should be considered as well, like SNPs in the brain-specific thyroid hormone transporter OATP1C1 which have been associated with fatigue and depression but not with neurocognitive functioning or preference for $\mathrm{T} 4+$
T3 [1]. Interestingly, a Danish RCT found two SNPs (Thr92Ala DIO2 and rs17606253 MCT10 -monocarboxylate transporter 10) associated with favored treatment: preference for T4 + T3 therapy was $42 \%$ when both SNPs were absent, $63 \%$ if one SNP was present, and $100 \%$ if both SNPs were present [35].

\section{Which patients would qualify for L-T4 + L-T3 combination therapy?}

The 2012 ETA guidelines suggest "that L-T4 + L-T3 combination therapy might be considered as an experimental approach in compliant L-T4 treated hypothyroid patients who have persistent complaints despite serum TSH values within the reference range, provided they have previously given support to deal with the chronic nature of their disease and associated autoimmune diseases have been ruled out. T4 + T3 combination therapy is not recommended in pregnant women and in patients with cardiac arrhythmias" [1]. These recommendations have been adopted by Italian and British Thyroid Associations, whereas the ATA takes a more neutral position [37]. It is further suggested that the combination therapy is discontinued if no improvement is experienced after three months. Concern about the long-term safety of $\mathrm{T} 4+\mathrm{T} 3$ combination therapy still exists, but the results of a 17-year observational population-based study in Scotland on liothyronine (T3) use are reassuring [38]. Compared to patients only taking L-T4 $(n=33955)$, those using L-T3 (with or without L-T4, $n=400$ ) had no increased risk of cardiovascular disease, atrial fibrillation or fractures after adjusting for age. There was no difference in the number of prescriptions for bisphosphonates or statins, but there was an increased risk of new prescriptions for antipsychotic medication (hazard ratio 2.26, CI 1.64-3.11) which was proportional to the number of L-T3 prescriptions [38]. A 2017 survey among ATA members looked for characteristics that would lead to alternative therapies in T4-treated hypothyroid patients [39]. Especially the presence of symptoms (adjusted odds ratio 25.6), but also low serum T3, the presence of $\mathrm{DIO} 2$ polymorphism and patient request (adjusted odds ratio's 2.3-2.6) increased physician's willingness to prescribe T3-containing therapy, whereas older age and comorbidities decreased willingness; athyreotic state, sex and body mass index had no effect. Demands for combination therapy increase in the USA, Canada, Australia, and most European countries [40, 41]. This is well illustrated by a sharp 3.8 fold increase in the number of applications for reimbursement of $\mathrm{T} 4+\mathrm{T} 3$ therapy in Denmark between the periods July 2012-June 2013 and July 2013-June 2014 (Fig. 1) [41]. This huge increase most likely was caused by extensive media coverage of 
hypothyroidism and its treatment. It looks the $\mathrm{T} 4+\mathrm{T} 3$ issue has become a real "hype". The Danish paper also provides much information on what is going on in real life with respect to combination therapy (Table 2) [41]. Certainly the 2012 ETA guidelines are not followed in many cases. For, the guidelines recommend prescriptions and dose adjustments should be done by accredited internists/endocrinologists and not by general practitioners and not at all by patients themselves. Of concern is the large proportion of patients whose serum TSH at diagnosis was $<10 \mathrm{mU} / \mathrm{l}$, meaning they had subclinical hypothyroidism which may lead to less benefit from therapy and possibly overtreatment $[7,8,42]$.

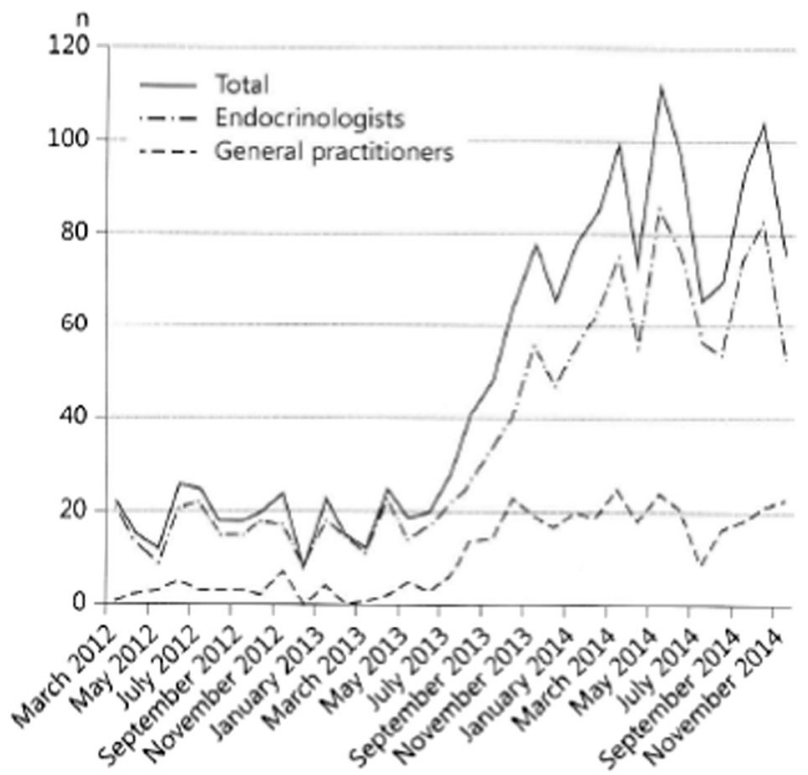

Fig. 1 Number of applications for reimbursement of L-T4 + L-T3 combination therapy in Denmark increased 3.8 fold in the period July 2013-June 2014 compared to July 2012-June 2013, most likely provoked by intense media coverage of hypothyroidism and its treatment [41]

\section{What is the appropriate dosage of L-T4 + L-T3 combination therapy?}

The recommended dosage of L-T4 + L-T3 combination therapy in the 2012 ETA guidelines is based on the assumption that euthyroidism can be reached simultaneously in all tissues of hypothyroid patients only by L$\mathrm{T} 4+\mathrm{L}-\mathrm{T} 3$ in a dose ratio that mimics the physiological $\mathrm{T} 4$ to $\mathrm{T} 3$ secretion ratio by the human thyroid gland (which is close to 13:1 by weight) [1]. The assumption, derived from the experimental animal studies by Morreale de Escobar et al., may or may not be true. The pharmacodynamic equivalence of L-T4 and L-T3 has been assessed in a randomized, double-blind, cross-over study in 10 thyroidectomized patients [43]. The target (TSH $\geq 0.5 \mathrm{mU} / \mathrm{L}$ but $\geq 1.5 \mathrm{mU} / \mathrm{L}$ for at least 30 days) was reached by an average daily dose of either $115 \pm 38.5 \mu \mathrm{g} \mathrm{L}-\mathrm{T} 4$ or $40 \pm$ $11 \mu \mathrm{g} \mathrm{L-T3}$ (L-T4 to L-T3 ratio $0.36 \pm 0.06$ ). It was concluded that therapeutic substitution of L-T4 by L-T3 was achieved at a ratio of approximately 3:1. In other words, $30 \mu \mathrm{g}$ T 4 can be substituted by $10 \mu \mathrm{g}$ T3 without changes in serum TSH. Thus, a simple method to arrive at the desired dose ratio between L-T4 and L-T3 is as follows. Dose $x$ is the daily L-T4 dose in $\mu \mathrm{g}$ that has resulted in a normal serum TSH. The required daily L-T3 dose in $\mu$ g (called $y$ ) is given by $y=x: 20$. The requested daily L-T4 dose in $\mu \mathrm{g}$ (called $z$ ) is given by $z=x-3 y$ (Table 3) [1]. Whereas L-T4 can be given once daily, the daily L-T3 dose should be divided -if possible- in two doses, one before breakfast and the largest one before sleeping [1]. The rationale for splitting the daily L-T3 dose in two (or even three) gifts is the relatively short half-life of L-T3, peak serum T3 values at 2-4 $\mathrm{h}$ after ingestion, and a physiological diurnal variation in serum T3 with zenith around $4 \mathrm{am}$ and nadir between 3 and $5 \mathrm{pm}$ [44]. It is suggested to start $\mathrm{T} 4+\mathrm{T} 3$ combination therapy in a L-T4:L-T3 dose ratio between $13: 1$ and $20: 1$ by

Table 2 "Real-life" data on T4 + T3 combination therapy in Denmark, according to an internet-based questionnaire study [41]

Respondents

Duration of hypothyroidism

TSH at diagnosis

Symptoms before start of $\mathrm{T} 4+\mathrm{T} 3$ therapy

Prescriptions

Dose adjustments

Duration $\mathrm{T} 4+\mathrm{T} 3$ therapy

Most recent TSH

Response to T4 + T3 therapy $n=293$ female $94 \%$, male $6 \% ;<40$ years $20 \%, 41-60$ years $63 \%, \geq 61$ years $17 \% ; 1^{\circ} / 2^{\circ}$ education $11 \%$, vocational or short $3^{\circ}$ education $28 \%, 3^{\circ}$ education $>3$ yr $60 \%$, no answer $1 \%$

$<1$ years $4 \%, 1-3$ years $15 \%, 3-10$ years $36 \%,>10$ years $45 \%$

Do not remember 26\%; <4 mU/L 26\%; 4-10 mU/L 18\%; 10-20 mU/L 11\%; 20-50 mU/L 6\%; >50 $\mathrm{mU} / \mathrm{L} 12 \%$

Tired $91 \%$, lack of energy $87 \%$, cognitive problems $83 \%$, musculoskeletal symptoms $76 \%$, weight problems $75 \%$, pain $49 \%$, constipation $42 \%$, depression $39 \%$

L-T4 + L-T3 therapy $43 \%$, desiccated thyroid $50 \%$, other drug $7 \%$, both L-T3 and desiccated $1 \%$

Physician (blood samples) 44\%, physician (symptoms) 17\%, myself (symptoms) 28\%, no answer $(11 \%)$

3-6 months $56 \%, 6-12$ months $16 \%, 1-3$ year $14 \%$, >3 year $10 \%$, no answer $4 \%$

$<0.01 \mathrm{mU} / \mathrm{L} 14 \%, 0.01-1.0 \mathrm{mU} / \mathrm{L} 54 \%, 1.0-2.5 \mathrm{mU} / \mathrm{L} 14 \%, 2.5-4.0 \mathrm{mU} / \mathrm{L} 8 \%,>4.0 \mathrm{mU} / \mathrm{L} 5 \%$, no answer $4 \%$

Miraculous $19 \%$, much better $43 \%$, better $22 \%$, no difference $6 \%$, worse $2 \%$, no answer $8 \%$ 
Table 3 Simple method for calculating appropriate L-T4 and $\mathrm{L}-\mathrm{T} 3$ dosages for $\mathrm{T} 4+\mathrm{T} 3$ combination therapy [1]
Table 4 Available formulations of L-T3 tablets, L-T3 + L-T4 combination tablets, and desiccated thyroid extract [44]

\begin{tabular}{llll}
\hline $\begin{array}{l}\text { T4 monotherapy dose } \mathrm{x}=\mathrm{L}-\mathrm{T} 4 \text { dose that } \\
\text { normalized TSH }\end{array}$ & $\begin{array}{l}100 \mu \mathrm{g} \mathrm{L}-\mathrm{T} 4= \\
\text { dose } \mathrm{x}\end{array}$ & $\begin{array}{l}150 \mu \mathrm{g} \mathrm{L}-\mathrm{T} 4= \\
\text { dose } \mathrm{x}\end{array}$ & $\begin{array}{l}200 \mu \mathrm{g} \text { L-T4 }= \\
\text { dose } \mathrm{x}\end{array}$ \\
$\begin{array}{ll}\text { T4 (dose } z)+T 3 \text { (dose y) combination therapy } \\
\text { L-T3 dose } y=x: 20\end{array}$ & $5 \mu \mathrm{g}$ & $7.5 \mu \mathrm{g}$ & $10 \mu \mathrm{g}$ \\
L-T4 dose $z=x-3 y$ & $85 \mu \mathrm{g}$ & $127.5 \mu \mathrm{g}$ & $170 \mu \mathrm{g}$ \\
L-T4 dose (round off) & $87.5 \mu \mathrm{g}$ & $125 \mu \mathrm{g}$ & $175 \mu \mathrm{g}$ \\
L-T4: L-T3 dose ratio & $17: 1$ & $17: 1$ & $17: 1$ \\
\hline
\end{tabular}

\begin{tabular}{llll}
\hline Brand name & T3 dose & T4 dose & Availability \\
\hline $\begin{array}{l}\text { L-T3 tablets } \\
\text { Cytomel }\end{array}$ & $5,25,50 \mu \mathrm{g}$ & & USA, Canada, Holland \\
Thybon & $20,100 \mu \mathrm{g}$ & & UK \\
Tertroxin & $20 \mu \mathrm{g}$ & Australia, South Africa \\
Liotyr & $5 \mu \mathrm{g}($ soft gel) & & Italy \\
L-T3+ L-T4 tablets & & & \\
Prothyroid & $10 \mu \mathrm{g}$ & $100 \mu \mathrm{g}$ & Germany \\
Novothyral & $5,15,20 \mu \mathrm{g}$ & $25,75,100 \mu \mathrm{g}$ & Europe \\
Thyreotom forte & $10,30 \mu \mathrm{g}$ & $40,120 \mu \mathrm{g}$ & Czech republic \\
Desiccated thyroid extract & & & \\
Nature thyroid per $65 \mathrm{mg}$ grain & $9 \mu \mathrm{g}$ & $38 \mu \mathrm{g}$ & USA \\
Westhroid pure per $65 \mathrm{mg}$ grain & $9 \mu \mathrm{g}$ & $38 \mu \mathrm{g}$ & USA \\
NP thyroid per $60 \mathrm{mg}$ grain & $9 \mu \mathrm{g}$ & $38 \mu \mathrm{g}$ & USA \\
Thyroid (erfa) per $60 \mathrm{mg}$ grain & $8 \mu \mathrm{g}$ & $35 \mu \mathrm{g}$ & Europe, Canada \\
Armour thyroid per $60 \mathrm{mg}$ grain & $9 \mu \mathrm{g}$ & $38 \mu \mathrm{g}$ & USA \\
\hline
\end{tabular}

weight [1]. The serum FT3/FT4 ratio (pmol/l to pmol/l) in hypothyroid patients replaced with L-T4 is 0.24 (IQR $0.20-0.28$ ), lower than the value of 0.32 (IQR $0.27-0.37$ ) in euthyroid controls [16]. In RCTs the serum FT3/FT4 ratio is 0.30 (IQR 0.25-0.45) during L-T4 + L-T3 combination therapy, higher than the value of 0.24 (IQR 0.18-0.25) during L-T4 monotherapy but still somewhat lower than in controls [1]. A retrospective observational study in Denmark reports on patients with persistent symptoms despite L-T4 therapy and normal serum TSH [45]. Treatment was changed into L-T4 + L-T3 combination therapy in a 17:1 ratio (weight/weight). After 12 months, 65\% were responders and $35 \%$ nonresponders. There were no differences between both groups in the decrease of serum T4 $(-18$ and $-4.5 \mathrm{nmol} / \mathrm{L}$ respectively) nor in the increase of serum T3 $(+0.28$ and $+0.25 \mathrm{nmol} / \mathrm{l}$, respectively).

\section{Which preparations can be used in L-T4 + L- T3 combination therapy and how should their use be monitored?}

The 2012 ETA guidelines recommend to use separate L-T4 and L-T3 tablets in combination therapy, as available combination tablets contain a L-T4/L-T3 dose ratio of 4:1,
5:1 and 10:1 (Table 4). These ratios are significantly different from the recommended ratios of 13:1 to 20:1. If dose adjustments are necessary, it is also more convenient to change the dose of just one of the components, preferably of L-T3 [1]. In view of the pharmacokinetics of L-T3, a slow release preparation of L-T3 would be welcome, but that has not been realized. Thyromax, a L-T3 tablet made with microcrystalline cellulose and magnesium stearate, was hoped to have a sustained $\mathrm{T} 3$ release profile, but it had a serum T3 profile similar to Cytomel [46, 47]. A single dose of T3 sulfate provided steady-state serum T3 concentrations for $48 \mathrm{~h}$, but nothing more has been heard about this interesting observation [48]. What has been accomplished since 2012, however, is the availability of L-T3 tablets of low strength (like $5 \mu \mathrm{g}$ Cytomel). Splitting tablets in halves comes in handy if low doses of 2.5 or $7.5 \mu \mathrm{g}$ L-T3 are required. This development undoubtedly has been driven by great interest in the combination therapy. On the negative side of this development one should note an unacceptable increase in the price of L-T3 tablets implemented by particular pharmaceutical companies. E.g. in the UK, the price of a single $20 \mu \mathrm{g}$ generic L-T3 tablet increased suddenly from 0.16 to $9.22 £$. The total monthly cost of L-T3 prescriptions for NHS England was $758975 £$ in August 2013; the figure was increased by almost ten times to $7018679 £$ 
Table 5 Suggestions for future research made in the 2012 ETA guidelines on the use of L-T4+L-T3 in the treatment of hypothyroidism [1]

1. Prospective studies in hypothyroid patients starting L-T4 therapy, comparing baseline characteristics between those who will and those who will not be satisfied with the outcome of L-T4 monotherapy.

2. Trials investigating the L-T4/L-T3 dose ratio that best approximates the serum FT4/FT3 concentration ratio in healthy subjects.

3. Randomized clinical trials comparing L-T4 + L-T3 combination therapy and L-T4 monotherapy in hypothyroid patients who have persistent symptoms and/or are carriers of polymorphisms in thyroid hormone transporters and deiodinases.

4. Studies with a slow-release preparation of L-T3.

5. Prospective studies assessing the long-term efficacy and safety of L-T4 + L-T3 combination therapy.

None of these suggestions have been realized seven years later in June 2019

by July 2018, despite fewer prescriptions [49]. This all resulted in widespread patient concern, media coverage, and to a motion in the House of Lords. The motion, moved by Lord Hunt of Kings Heath, reads "That this house regrets that the Branded Health Service Medicines (Costs) Regulations 2018 do not propose any action be taken in respect of the high cost charged by Concordia and other companies for the drug Liothyronine for the treatment of hypothyroidism, thereby depriving patients of the use of that essential drug" [50]. Lastly, DTE was preferred by patients over L-T4 in a RCT [51] and in a website-based survey [5]. DTE is not recommended in guidelines, but patients' preference for the drug should be explored in more depth.

\section{What are areas for future research on this topic?}

Since the ETA guidelines were published in 2012, many issues surrounding $\mathrm{T} 4+\mathrm{T} 3$ combination therapy have become more clear. Much progress has been made in elucidating the putative role of SNPs in type 2 deiodinase (like Thr92Ala), but why some patients on L-T4 keep persistent symptoms despite a normal serum TSH, remains obscure. The controversial issue of combination therapy in my opinion can only be solved by doing many more clinical trials. It is a sobering thought that so far none of the studies suggested in the 2012 guidelines, have been realized (Table 5). This is even more worrisome because dissatisfaction with treatment outcomes is growing, and the clinical problem now has obtained political overtones. Clinical research becomes more difficult when politics are involved.

\section{Compliance with ethical standards}

Conflict of interest The author declares that he has no conflict of interest.

Ethical approval This article does not contain any studies with human participants performed by the author.

Informed consent The present paper is a review of papers published in the literature. For informed consent of participants to these previous studies, see original papers.

Publisher's note: Springer Nature remains neutral with regard to jurisdictional claims in published maps and institutional affiliations.

Open Access This article is distributed under the terms of the Creative Commons Attribution 4.0 International License (http://crea tivecommons.org/licenses/by/4.0/), which permits unrestricted use, distribution, and reproduction in any medium, provided you give appropriate credit to the original author(s) and the source, provide a link to the Creative Commons license, and indicate if changes were made.

\section{References}

1. W.M. Wiersinga, L. Duntas, V. Fadeyev, B. Nygaard, M.P. Vanderpump, 2012 ETA guidelines: the use of L-T4 + L-T3 in the treatment of hypothyroidism. Eur. Thyroid J. 1, 55-71 (2012)

2. P. Saravanan, W.-F. Chau, N. Roberts, K. Vedhara, R. Greenwood, C.M. Dayan, Psychological well-being in patients on 'adequate' doses of L-thyroxine: results of a large, controlled community-based questionnaire study. Clin. Endocrinol. 57, 577-585 (2002)

3. E.M. Wekking, B.C. Appelhof, E. Fliers, A.H. Schene, T. Huyser, J.G.P. Tijssen, W.M. Wiersinga, Cognitive functioning and wellbeing in euthyroid patients on thyroxine replacement therapy for primary hypothyroidism. Eur. J. Endocrinol. 153, 747-753 (2005)

4. V. Panicker, J. Evans, T. Bjoro, B.O. Asvold, C.M. Dayan, O. Bjerkeset, A paradoxical difference in relationship between anxiety, depression and thyroid function in subjects on and not on T4: findings from the HUNT study. Clin. Endocrinol. 71, 574-580 (2009)

5. S.J. Peterson, A.R. Cappola, M.R. Castro, C.M. Dayan, A.P. Farwell, J.V. Hennessey et al. An online survey of hypothyroid patients demonstrates prominent dissatisfaction. Thyroid $\mathbf{2 8}$, 707-721 (2018)

6. P.N. Taylor, A. Iqbal, C. Minassian, A. Sayers, M.S. Draman, R. Greenwood et al. Falling threshold for treatment of borderline elevated thyrotropin levels-balancing benefits and risks: evidence from a large community-based study. JAMA Intern. Med. 174, 32-39 (2014)

7. D.J. Stott, N. Rodondi, P.,M. Kearney, I. Ford, R.G.J. Westendorp, S.P. Mooijaart et al. Thyroid hormone therapy for older adults with subclinical hypothyroidism. N. Engl. J. Med. 376, 2534-2544 (2017)

8. M. Feller, M. Snel, E. Moutzouri, D.C. Bauer, M. de Montmollin, D. Aujesky et al. Association of thyroid hormone therapy with quality of life and thyroid-related symptoms in patients with subclinical hypothyroidism: a systematic review and metaanalysis. JAMA 320, 1349-1359 (2018)

9. R.P. Peeters, Subclinical hypothyroidism. N. Engl. J. Med. 376, 2556-25655 (2017) 
10. R. Dew, K. King, O.E. Okosieme, S. Pearce, G. Donovan, P.N. Taylor et al. towards treatment of hypothyroidism in general practice: an in-depth qualitative interview study. BJGP Open 1, bjgopen17X100977 (2017). https://doi.org/10.3399/bjgopen17X10097

11. R. Dew, K. King, O.E. Okosieme, S.H. Pearce, G. Donovan, P.N. Taylor et al. Attitudes and perceptions of health professionals towards management of hypothyroidism in general practice: a qualitative interview study. BMJ Open 8, e019970 (2018). https:// doi.org/10.1136/bmjopen-2017-019970

12. K. Boelaert, P.R. Newby, M.J. Simmonds, R.L. Holder, J.D. CarrSmith, J.M. Heward et al. Prevalence and relative risk of other autoimmune diseases in subjects with autoimmune thyroid disease. Am. J. Med. 123, 183.e1-183.e9 (2010)

13. I. Guldvog, L.C. Reitsma, L. Johnsen, A. Lauzike, C. Gibbs, E. Carlsen et al. Thyroidectomy versus medical management for euthyroid patients with Hashimoto disease and persisting symptoms. A randomized trial. Ann. Int. Med. (2019). https://doi.org/ 10.7326/M18-0284

14. S.J. Peterson, E.A. McAninch, A.C. Bianco, Is a normal TSH synonymous with "euthyroidism" in levothyroxine monotherapy? J. Clin. Endocrinol. Metab. 101, 4694-4973 (2016)

15. D. Gullo, A. Latina, F. Frasca, R. LeMoli, G. Pellegritti, R. Vigneri et al. Levothyroxine monotherapy cannot guarantee euthyroidism in all athyreotic patients. PLoS ONE 6, e22552 (2011)

16. J.P. Walsh, L.C. Ward, V. Burke, C.I. Bhagat, L. Shiels, D. Henley et al. Small changes in thyroxine dosage do not produce measurable changes in hypothyroid symptoms, wellbeing, or quality-in-life: results of a double-blind, randomized clinical trial. J. Clin. Endorinol. Metab. 91, 2624-2630 (2006)

17. M.H. Samuels, I. Kollobova, M. Niederhausen, J.S. Janowsky, K. G. Schuff, Effects of altering levothyroxine (L-T4) doses on quality of life, mood, and cognition in L-T4 treated subjects. J. Clin. Endocrinbol. Metab. 103, 1997-2008 (2018)

18. M.H. Samuels, I. Kolobova, M. Niederhausen, J.Q. Purnell, K.G. Schuff, Effects of altering levothyroxine dose on energy expenditure and body composition in subjects treated with LT4. J. Clin. Endocrinol. Metab. 103, 4163-4175 (2018)

19. M. Ito, A. Miyauchi, S. Morita, T. Kudo, E. Nishihara, M. Kihara et al. TSH-suppressive doses of levothyroxine are required to achieve preoperative native serum triiodothyronine levels in patients who have undergone total thyroidectomy. Eur. J. Endocrinol. 167, 373-378 (2012)

20. D. Strich, C. Chay, G. Karavani, S. Edri, D. Gillis, Levothyroxine therapy achieves physiological FT3/FT4 ratios at higher than normal TSH levels: a novel justification for T3 supplementation? Horm. Metab. Res. 50, 827-831 (2018)

21. B. Gereben, E.A. McAninch, M.O. Ribeiro, A.C. Bianco, Scope and limitations of iodothyronine deiodinases in hypothyroidism. Nat. Rev. Endocrinol. 11, 642-652 (2015)

22. J.P. Werneck de Castro, T.L. Fonseca, C.B. Ueta, E.A. McAninch, S. Abdalla, G. Wittmann et al. Differences in hypothalamic type 2 deiodinase ubiquitination explain localized sensitivity to thyroxine. J. Clin. Investig. 125, 769-781 (2015)

23. M. Ito, A. Miyauchi, M. Hisakado, W. Yoshioka, A. Ide, T. Kudo et al. Biochemical markers reflecting thyroid function in athyreotic patients on levothyroxine monotherapy. Thyroid 27, 484-490 (2017)

24. E.A. McAninch, K.B. Rajan, C.H. Miller, A.C. Bianco, Systemic thyroid hormone status during levothyroxine therapy in hypothyroidism: a systematic review and meta-analysis. J. Clin. Endocrinol. Metab. 103, 4533-4542 (2018)

25. R. Hoermann, J.E. Midgley, R. Larisch, J.W. Dietrich, Is pituitary TSH an adequate measure of thyroid hormone-controlled homeostasis during thyroxine treatment? Eur. J. Endocrinol. 168, 271-280 (2013)
26. V. Panicker, P. Saravanan, B. Vaidya, J. Evans, A.T. Hattersley, T.M. Frayling, C.M. Dayan, Common variation in the DIO2 gene predicts baseline psychological well-being and response to combination thyroxine plus triiodothyronine therapy in hypothyroid patients. J. Clin. Endocrinol. Metab. 94, 1623-1629 (2009)

27. M.G. Castagna, M. Dentice, S. Cantara, R. Ambrosio, F. Maino, T. Porcelli et al. DIO2 Thr92Ala reduces deiodinase-2 activity and serum-T3 levels in thyroid-deficient patients. J. Clin. Endocrinol. Metab. 102, 1623-1630 (2017)

28. M. Medici, L. Chaker, R.P. Peeters, A step forward in understanding the relevance of genetic variation in type 2 deiodinase. $\mathrm{J}$. Clin. Endocrinol. Metab. 102, 1775-1778 (2017)

29. H.J.C.M. Wouters, H.C.M. van Loon, M.M. van der Klauw, M.F. Elderson, S.N. Slagter, A. Muller Kobold et al. No effect of the Thr92Ala polymorphism of deiodinase- 2 on thyroid hormone parameters, health-related quality of life, and cognitive functioning in a large population-based cohort study. Thyroid 27, 147-155 (2017)

30. E.A. McAninch, S. Jo, N.Z. Preite, E. Farkas, P. Mohacsik, C. Fekete et al. Prevalent polymorphism in thyroid hormone-activating enzyme leaves a genetic fingerprint that underlies associated clinical syndromes. J. Clin. Endocrinol. Metab. 100, 920-933 (2015)

31. S. Jo, T.L. Fonseca, B.M.L.C. Bocco, G.W. Fernandes, E.A. McAninch, A.P. Bolin et al. Type 2 deiodinase polymorphism causes ER stress and hypothyroidism in the brain. J. Clin. Investig. 129, 230-245 (2019)

32. H.B. Burch, K.D. Burman, D.S. Cooper, J.V. Hennessey, A 2013 survey of clinical practice patterns in the management of primary hypothyroidism. J. Clin. Endocrinol. Metab. 99, 2077-2085 (2014)

33. J. Kaminski, F.Y. Miasaki, G. Paz-Filho, H. Graf, G.A. de Carvalho, Treatment of hypothyroidism with levothyroxine plus liothyronine: a randomized, double-blind, crossover study. Arch. Endocrinol. Metab. 60, 562-572 (2016)

34. R. Hoermann, J.E.M. Midgley, R. Larisch, J.W. Dietrich, Lessons from randomised clinical trials for triiodothyronine treatment of hypothyroidism: have they achieved their objectives? J. Thyroid Res. (2018). https://doi.org/10.1155/2018/3239197

35. A. Carlé, J. Faber, R. Steffensen, P. Laurberg, B. Nygaard, Hypothyroid patients encoding combined MCT10 and DIO2 gene polymorphisms may prefer $\mathrm{L}-\mathrm{T} 3+\mathrm{L}-\mathrm{T} 4$ combination treatment data using a blind, randomized clinical study. Eur. Thyroid J. 6, 143-151 (2017)

36. L.F. Michaelsson, J.L. la Cour, B.B. Medici, T. Watt, J. Faber, B. Nygaard, Levothyroxine/liothyronine combination therapy and quality of life: is it all about weight loss? Eur. Thyroid J. 7, 243-250 (2018)

37. J.V. Hennessey, R. Espaillat, Current evidence for the treatment of hypothyroidism with levothyroxine/levotriiodothyronine combination therapy versus levothyroxine monotherapy. Int. J. Clin. Pract. 72, e13062 (2018)

38. G.P. Leese, E. Soto-Pedre, L.A. Donnelly, Liothyronine use in a 17 year observational population-based study - the TEARS study. Clin. Endocrinol. 85, 918-925 (2016)

39. J. Jonklaas, E. Tefera, N. Shara, Physician choice of hypothyroidism therapy: influence of patient characteristics. Thyroid $\mathbf{2 8}$, 1416-1424 (2018)

40. J. Jonklaas, E. Tefera, N. Shara, Prescribing therapy for hypothyroidism: influence of physician charcteristics. Thyroid 29, 44-52 (2019)

41. L.F. Michaelsson, B.B. Medici, J.L. la Cour, C. Selmer, M. Roder, H. Perrild et al. Treating hypothyroidism with thyroxine/triiodothyronine combination therapy in Denmark: following guidelines or following trends?. Eur. Thyroid J. 4, 174-180 (2015)

42. B.B. Medici, B. Nygaard, J.L. la Cour, M.K. Grand, V. Siersma, D.R. Nicolaisdottir et al. Changes in prescription routines for treating hypothyroidism between 2001 and 2015 - an 
observational study of 929,684 primary care patients in Copenhagen. Thyroid 29 (2019). https://doi.org/10.1089/thy.2018.0539

43. F.S. Celi, M. Zemskova, J.D. Linderman, N.I. Babar, M.C. Skarulis, W. Csako et al. The pharmacodynamics equivalence of levothyroxine and liothyronine: a randomized, double blind, cross-over study in thyroidectomized patients. Clin. Endocrinol. 72, 709-715 (2010)

44. C. Dayan, V. Panicker, Management of hypothyroidism with combination thyroxine (T4) and triiodothyronine (T3) hormone replacement in clinical practice: a review of suggested guidance. Thyroid Res. 11 (2018). https://doi.org/10.1186/s13044-018-0045-x

45. B.B. Medici, J.L. la Cour, L.F. Michaelsson, J.O. Faber, B. Nygaard, Neither baseline nor changes in serum triiodothyronine during levothyroxine/liothyronine combination therapy predict a positive response to this treatment modality in hypothyroid patients with persistent symptoms. Eur. Thyroid J. 6, 89-93 (2017)

46. J. Jonklaas, K.D. Burman, H. Wang, K. Latham, Single dose T3 administration: kinetics and effects on biochemical and physiologic parameters. Ther. Drug Monit. 37, 110-118 (2015)
47. J. Jonklaas, K.D. Burman, Daily administration of short-acting liothyronine is associated with significant triiodothyronine excursions and fails to alter thyroid-responsive parameters. Thyroid 26, 770-778 (2016)

48. F. Santini, M. Giannetti, I. Ricco, G. Querci, G. Saponati, D. Bokor et al. Steady-state serum T3 concentrations for $48 \mathrm{~h}$ following the oral administration of a single dose of 3,5,3'-triiodothyronine sulfate (T3S). Endocr. Pract. 20, 680-689 (2014)

49. P.N. Taylor, S. Razvi, I. Muller, J. Wass, C.M. Dayan, K. Chatterjee, K. Boelaert, Liothyronine cost and prescriptions in England. Lancet Diab Endocrinol. 7, 11-12 (2019)

50. https://hansard.parliament.uk/Lords/2018-06-20/debates/ 5A689F14-D2F8-4796-8732-CBD0E3B3E508/BrandedHea lthServiceMedicines(Costs)Regulations 2018

51. T.D. Hoang, C.H. Olsen, V.Q. Mai, P.W. Clyde, M.K. Shakir, desiccated thyroid extract compared with levothyroxine in the treatement of hypothyroidism: a randomized, double-blind, crossover study. J. Clin. Endocrinol. Metab. 98, 1982-1990 (2013) 